\title{
PODE A MÁQUINA JULGAR? CONSIDERAÇÕES SOBRE O USO DE INTELIGÊNCIA ARTIFICIAL NO PROCESSO DE DECISÃO JUDICIAL
}

\author{
Samuel Rodrigues de Oliveira* \\ Ramon Silva Costa**
}

\begin{abstract}
RESUMO: Atualmente, sistemas baseados em inteligência artificial (IA) têm sido utilizados no processo de argumentação jurídica e de tomada de decisões judiciais. Apesar da pretensão de se utilizar softwares para a solução de casos jurídicos, acreditamos não ser possível alcançar a correção de uma decisão judicial sem a atividade humana. O presente trabalho objetiva investigar se, considerados os aspectos pertinentes da argumentação jurídica de Alexy, seria possível atribuir a uma IA a atividade de julgar, a partir das teorias de Searle. Metodologicamente, emprega-se o método dedutivo somado a revisão bibliográfica a fim de se responder ao problema apresentado.
\end{abstract}

Palavras-chave: Argumentação Jurídica; Decisão Judicial; Filosofia do Direito; Filosofia da Mente; Inteligência Artificial.

\section{CAN MACHINE JUDGE? CONSIDERATIONS ON THE USE OF ARTIFICIAL INTELLIGENCE IN THE PROCEDURE OF JUDICIAL DECISION}

\begin{abstract}
Nowadays, systems based on artificial intelligence (AI) have been used in the process of legal argumentation and judicial decision making. Despite the pretension of using software for the solution of legal cases, we believe that it is impossible to achieve the correction of a judicial decision without human activity. The present work aims to investigate whether, considering the pertinent aspects of Alexy's Theory of Legal Argumentation, it would be possible to grant an AI the activity of judging, from the perspective of Searle's theories. Methodologically, the deductive method is used in addition to bibliographic review to answer the introduced problem.
\end{abstract}

Keywords: Artificial Intelligence; Judicial Decision; Legal Argumentation; Philosophy of Law; Philosophy Of Mind;

\footnotetext{
* Graduado em Direito e mestrando em Direito e Inovação pela Universidade Federal de Juiz de Fora (UFJF). samuelrdeoliveira@ gmail.com. Rua José Lourenço Kelmer, s/n - Faculdade de Direito - Campus Universitário Bairro São Pedro - CEP: 36036-900 - Juiz de Fora - MG.

**Graduado em Direito pela Universidade Federal Fluminense (UFF) e mestrando bolsista CAPES em Direito e Inovação pela Universidade Federal de Juiz de Fora (UFJF). ramoncostta@outlook.com. Rua José Lourenço Kelmer, s/n - Faculdade de Direito - Campus Universitário - Bairro São Pedro - CEP: 36036-900 - Juiz de Fora - MG.
} 


\section{INTRODUÇÃO}

Atualmente, sistemas baseados em inteligência artificial (IA) já operam nas mais diversas áreas do cotidiano. Inúmeras realizações tecnológicas que antes pareciam pertencer apenas à ficção científica acabaram por se tornar reais e pertencentes ao dia-a-dia humano (RICHARDS, 2013). Diante de sua crescente ubiquidade e enorme potencial de comercialização, a inteligência artificial tem gerado investimentos maciços por parte do setor privado, e o prognóstico que se apresenta é que seu uso se torne cada vez mais disseminado em um futuro próximo, avançando, inclusive, para a esfera pública - o que já se verifica em certa medida. Concomitantemente ao desenvolvimento do setor de tecnologia desde meados do século passado, ocorreram mudanças paradigmáticas e substanciais das noções de democracia e direitos fundamentais, o que gerou um aumento de funções estatais, culminando na transformação do próprio Estado, o qual passou a assumir demandas mais complexas e em maior número (DUARTE e GALIL, 2017).

Nesse sentido, diante da crescente demanda pela atuação do Estado, a tendência mundial - à qual o Brasil tem se atentado - é implementar atividades e serviços públicos alicerçados por sistemas de IA (EGGERS, SCHATSKY e VIECHNICKI, 2017). Estudos recentes indicam que os benefícios mais óbvios no uso da IA pela gestão pública são aqueles que possam reduzir encargos administrativos, ajudar a resolver os problemas de alocação de recursos e assumir tarefas significativamente complexas e indicam que hoje os serviços estão concentrados em cinco categorias, quais sejam, responder questões, preencher e pesquisar documentos, gerenciamento de pedidos, tradução e elaboração de documentos (MEHR, 2017).

Nessa perspectiva, no âmbito do Direito, alguns sistemas jurídicos inteligentes surgiram para tentar solucionar problemas através da análise de precedentes, a exemplo do ROSS, que é, segundo o site da empresa responsável por sua criação, uma avançada ferramenta de pesquisa jurídica que emprega o poder da inteligência artificial para tornar o processo de pesquisa mais eficiente. ROSS é projetado para ler e entender a linguagem jurídica, postular hipóteses, pesquisar e gerar respostas fundamentadas para respaldar as suas conclusões, tendo sido recentemente "contratado" por uma firma de advogados nos Estados Unidos da América.

No Brasil, o maior e mais complexo sistema de IA em operação é batizado de VICTOR, resultado de iniciativa do Supremo Tribunal Federal, em parceria com a 
Universidade de Brasília (UnB), com vistas a conhecer e aprofundar a discussão sobre as aplicações de IA no Judiciário. O projeto, que se encontra em fase inicial, tem como objetivo primário ler todos os recursos extraordinários que sobem para o STF e identificar quais estão vinculados a determinados temas de repercussão geral, ato que, embora represente apenas uma parte da fase inicial do processamento dos recursos no Tribunal, envolve um alto nível de complexidade em aprendizado de máquina. Posteriormente, pretende-se que o software atue no pré-processamento de recursos extraordinários logo após sua interposição, o que visa antecipar o juízo de admissibilidade quanto à vinculação a temas com repercussão geral e acelerar a tramitação dos processos no STF.

Merecedor de destaque é o emprego de determinados sistemas jurídicos inteligentes como o denominado "Public Safety Assessment" - em tradução livre, "avaliação de segurança pública" - em determinados estados dos Estados Unidos da América. Em termos gerais, a prática estadunidense - e que se verifica de modo semelhante no Canadá e Reino Unido - consiste em aplicar na condenação criminal e na execução da pena determinadas predições matemáticas, fundadas em análises estatísticas e cruzamento de dados por meio de softwares, de modo a se determinar o quantum de pena a ser atribuído ao réu, bem como a quais benefícios fará jus no curso da execução penal (UCHÔAS, ALVES e TOLEDO, 2017; UCHÔAS, 2018). Sobre estes sistemas, discorrer-se-á mais detalhadamente no desenvolvimento do trabalho.

Face a essa situação, o objetivo da presente pesquisa é investigar se é possível atribuir a atividade jurisdicional, nomeadamente a capacidade de decidir, a uma "máquina" com inteligência artificial. A partir de reflexões nos âmbitos da filosofia do Direito e da filosofia da mente, a hipótese levantada é que a atividade de julgar é um ato essencialmente humano, e, portanto, não poderia ser delegado a um sistema de IA. Destarte, utilizar-se-á como guia a Teoria da Argumentação Jurídica de Robert Alexy (2005), analisando-se a concepção de IA sob a perspectiva da filosofia da mente de John Searle.

\section{METODOLOGIA}

Metodologicamente, a pesquisa que se pretendeu realizar é de cunho epistemológico. Segundo Monteiro e Savedra (2001), a pesquisa epistemológica implica atividade de pesquisa de cunho teórico ou filosófico, interessando-se sobre os conceitos e categorias fundamentais da ciência do Direito, seus paradigmas, os fundamentos do discurso jurídico, os valores 
informadores das normas jurídicas, bem como pelos conceitos jusfilosóficos. Esse tipo de pesquisa tem como técnica, $i$. e., procedimentos de pesquisa característicos, a pesquisa bibliográfica e, subsidiariamente, a pesquisa documental. Nesse sentido, realizou-se pesquisa qualitativa de revisão bibliográfica, e, mediante o método dedutivo, buscou-se obter respostas ao questionamento apresentado na introdução do presente trabalho. Caracteriza-se o método dedutivo por ser um processo pelo qual empregam-se cadeias de raciocínio, com base em enunciados ou premissas, chegando-se a uma conclusão necessária, em virtude da correta aplicação de regras lógicas. Assim, a partir de tal método, intentou-se compreender as características essenciais referentes à inteligência artificial e aos sistemas jurídicos inteligentes, bem como apreender os elementos mais importantes da filosofia do Direito de Alexy, de modo a se responder o problema exposto.

Para tanto, o presente trabalho procurou, inicialmente, discutir o que são a inteligência artificial e os sistemas jurídicos inteligentes, e como se dá a aplicação de tais tecnologias hodiernamente no Direito. Posteriormente, buscou-se compreender o papel da argumentação jurídica na atividade jurisdicional, especialmente no processo de decisão judicial; analisou-se como tem sida aplicada a inteligência artificial no Direito sob uma pretensa alegação de imparcialidade da decisão, e intentou-se demonstrar como, na realidade, os sistemas jurídicos inteligentes são passíveis a críticas por não atenderem determinadas premissas fundamentais da argumentação jurídica. Finalmente, apresentam-se algumas considerações a título de conclusão para o questionamento aqui levantado.

\section{A INTELIGÊNCIA ARTIFICIAL, OS SISTEMAS JURÍDICOS INTELIGENTES E SUA APLICAÇÃO NO DIREITO}

Conquanto inexista consenso na literatura especializada sobre o conceito de inteligência artificial, é possível afirmar, em linhas gerais, tratar-se da tentativa de reprodução, em sistemas artificiais, da cognição humana e seus mais variados componentes, como o aprendizado, a memória e o processo de tomada de decisões. Uma boa definição acerca do conceito de IA, contudo, é aquela formulada por John McCarthy, considerado o "pai da inteligência artificial", que formulou o conceito nos seguintes termos: fazer com que uma máquina se comporte de maneira que, caso se tratasse de um ser humano, seria considerada inteligente (MCCARTHY, 2000).

Adota-se, neste trabalho, uma definição de inteligência artificial que se enquadra 
naquilo que Searle, teórico da filosofia da mente, denomina "IA fraca". Partindo-se do pressuposto de que programas de computadores, assim como os computadores em si, são ferramentas úteis para o estudo da mente humana e o desenvolvimento de tecnologias, podemos considerar um programa de inteligência artificial como sendo, no máximo, a simulação de um processo cognitivo, mas não um processo cognitivo per se. Em outras palavras, sistemas de IA podem agir de forma inteligente, agir como se fossem inteligentes ou como se tivessem mentes. Assim, esses sistemas, apesar de agirem de forma inteligente, não seriam entidades genuinamente inteligentes, mas, no máximo simulações de comportamentos inteligentes, não tendo raciocínio nem vontades, pois a máquina se baseia no insumo do conhecimento fornecido por um programador, necessariamente humano (SEARLE, 1997, c).

Por outro ladro, adeptos da noção de "IA forte" acreditam que a mente está para o cérebro da mesma maneira que um software está para o hardware do computador (SEARLE, 1997c, p. 26). Essa visão tem por consequência a constatação de que não há nada essencialmente biológico na mente humana; nesse sentido, o cérebro integra, por acaso, o grande número de tipos de computadores que poderiam sustentar os programas que compõem a inteligência humana. Seguindo esta visão, qualquer sistema físico que tivesse o programa certo, com inputs e outputs adequados, teria uma mente exatamente no mesmo sentido em que humanos possuem uma mente. Então, como no exemplo dado por Searle, se você fez um computador com latas velhas de cerveja movidas por moinhos de vento e esse computador tivesse o programa certo, teria que se considerar que esse computador tem uma mente. Em outras palavras, qualquer sistema físico no qual se instalasse o programa correto possuiria uma mente, no mesmo sentido que seres humanos as possuem.

O único impedimento à replicação da consciência humana seria, portanto, o fato de ainda não terem sido criado hardwares e softwares necessários para tanto, tratando-se apenas de uma questão de tempo até que fosse possível replicar a consciência humana. Para os autores que acreditam em tal visão, os cérebros e mentes artificiais seriam equivalentes, em todos os aspectos, aos cérebros e mentes humanas (SEARLE, 2003, p. 28-29). No presente trabalho, repisa-se, será adotada a concepção de Inteligência Artificial como IA fraca, consoante o entendimento do referido autor.

Destaca-se que o atual entusiasmo no que diz respeito à pesquisa e desenvolvimento de tecnologias de inteligência artificial teve início aproximadamente em 2010, e foi movido pelos seguintes fatores: existência de métodos estatísticos e probabilísticos cada vez mais 
sofisticados; disponibilidade de um número expansivo de dados; acessibilidade a um enorme poder computacional a baixo custo; e a crescente adequação de ambientes às novas tecnologias, como a automação residencial e a criação de cidades 'inteligentes' (FLORIDI et al., 2017). Tais fatores, que se retroalimentam, possibilitaram o crescimento exponencial da criação e aperfeiçoamento de sistemas de IA nos últimos anos, não aparentando ser uma tendência passageira.

Pontua-se que, quando se trata de produzir simulações em termos de conhecimento num âmbito específico, discutem-se os chamados "sistemas inteligentes". Destarte, um programa de computador concebido e construído com o auxílio de um especialista em Direito, para resolver problemas específicos na área jurídica é um "sistema jurídico inteligente" (BELLOSO MARTÍN, 2015, p. 127). Seguindo tal lógica, os modelos de argumentação jurídica artificial hoje existentes focam em técnicas de inteligência artificial que permitam a existência de modelos de raciocínio jurídico - e.g. a análise de precedentes - como forma de garantir uma decisão racionalmente justificada, sendo a argumentação jurídica o meio de assegurar essa finalidade; isso deriva de uma perspectiva processual da decisão judicial, consoante a qual "o argumento legal é entendido tanto como um elemento de justificação da decisão", quanto "como um elemento de explicação no que se refere à relação lógica entre os argumentos e a pretensão" (MOZETIC, 2017).

Segundo Mozetic (2017), é de interesse de muitos juristas a ideia de potencializar a representação do conhecimento jurídico mediante a utilização de programas de computador, bem como o desenvolvimento de softwares com capacidade de simular decisões judiciais. Alguns autores, como Gordon (1993), Cella e Wojciechowski (2014), dentre outros, têm centrado a sua investigação acerca do uso de IA no campo da argumentação como um processo dialético, de negociação, a partir da problematização da aceitabilidade e comparação de argumentos. Assim, como se entende que a argumentação jurídica vai desempenhar um papel importante no processo de justificação das decisões judiciais e, como a maior parte do objeto de técnicas de inteligência artificial é permitir a existência de modelos de raciocínio jurídico como forma de garantir uma decisão racionalmente justificada, a argumentação jurídica também tem sido considerada como o meio de assegurar essa finalidade nos sistemas jurídicos inteligentes.

A título exemplificativo, pode-se tomar o fato de o poder judiciário norte-americano utilizar programas de computador para avaliar o "grau de periculosidade do réu", e, por meio de algoritmos, determinar o risco de reincidência do acusado naquela mesma prática delitiva. 
A partir da avaliação, esses instrumentos atribuem scores aos indivíduos condenados, que os classificam como tendo baixa, média ou alta probabilidade para o cometimento reiterado de determinado crime. A principal função desses softwares é a constatação de padrões, aplicáveis aos réus, para revelar um determinado risco de reincidir. Sob a promessa de "segurança, equidade e justiça”, programas como o já citado Public Safety Assessment verificam a probabilidade de um resultado ocorrido em uma população se repetir, permitindo que a decisão judicial possa ser considerada como fundamentada em evidências. Nesse sentido:

Essa técnica inovadora, fundada em análise estatística e tratamento de dados por softwares, visa o prognóstico de risco de violência, auxiliando os juízes a manter encarcerados os indivíduos que, eventualmente, representem alguma espécie de risco social. A classificação influenciará no quantum de pena que será atribuído ao réu, bem como a quais benefícios ele fará jus no curso da execução penal. [...] Contudo, ao escolher em quais casos os testes devem ser aplicados, é possível afirmar que, embora os resultados sejam estatísticos, não estão livres das preferências pessoais. Também não há evidências empíricas de que o emprego dessas tecnologias torna as decisões mais racionais (Hart, Michie e Cooke, 2007, p. 5) o que influencia negativamente a argumentação dos juízes nas decisões envolvendo resultados de testes preditivos (UCHÔA, 2018).

Destarte, uma vez que mesmo a utilização de inteligência artificial não permite constatar que as decisões sejam mais racionais, tampouco que sejam livres de preferências pessoais de seus programadores e daqueles que a utilizam, é possível perceber, desde já, que independentemente de quão completo seja o sistema de apoio à decisão, tanto tecnicamente como juridicamente descrevendo, uma máquina não pode substituir a apreciação feita pelo juiz.

\section{A ARGUMENTAÇÃo JURÍDICA, A FILOSOFIA DO DIREITO E SUA APLICAÇÃO NOS SISTEMAS JURÍDICOS INTELIGENTES}

A prática jurídica consiste, fundamentalmente, em argumentar, e o trabalho dos órgãos jurisdicionais e, em geral, dos aplicadores do direito, consiste principalmente em produzir argumentos para a resolução de casos, sejam eles concretos (individuais) ou genéricos, reais ou fictícios. Segundo Manuel Atienza (2005), argumentar constitui, definitivamente, a atividade central dos juristas e se pode dizer inclusive que há muito poucas profissões - se é que há alguma - em que a argumentação tenha um papel mais importante que no Direito. 
Em princípio, podem-se apontar três áreas distintas em que se efetuam argumentações jurídicas, quais sejam, na produção de normas jurídicas; na aplicação das normas jurídicas; e na dogmática jurídica. Assim:

La dogmática es, desde luego, una actividad compleja en la que cabe distinguir esencialmente estas tres funciones: 1) suministrar criterios para la producción del derecho en las diversas instancias en que ello tiene lugar; 2) suministrar criterios para la aplicación del derecho; 3) ordenar y sistematizar un sector del ordenamiento jurídico (ATIENZA, 2005, p. 2).

Destarte, dentre as três áreas referidas acima, pode-se afirmar que na aplicação das normas jurídicas é que se encontra o âmbito privilegiado de argumentação, uma vez que, dentre todos os operadores do Direito, os juízes são os únicos que verdadeiramente argumentam - supostamente - suas decisões. Ou, ao menos, são os únicos profissionais jurídicos que têm procurado produzir um estilo mais depurado e persuasivo de argumentação jurídica (CELLA e WOJCIECHOWSKI, 2014, p. 271).

No que concerne à aplicação do direito, o positivismo jurídico, sobretudo a partir de Kelsen e Hart, diagnosticou corretamente o que se chama "textura aberta" do direito, isto é, o fato de que o processo de interpretação e aplicação do direito não leva a uma única resposta correta, mas, pelo contrário, conduz a uma pluralidade de soluções igualmente admitidas dentro da moldura jurídica conformada pelas regras e princípios contidos no ordenamento (CARVALHO, 2013). O positivismo jurídico, contudo, não foi capaz de desenvolver teorias interpretativas que solucionassem ou minimizassem o problema da pluralidade de soluções.

Nesse sentido, a Teoria da Argumentação Jurídica de Alexy atina-se precisamente ao problema da argumentação legal, da interpretação e aplicação do direito. Alexy (2001, p. 17) inicia sua obra homônima com uma citação de Larenz, que preleciona que "ninguém mais pode afirmar seriamente que a aplicação das leis nada mais envolva (grifo do autor) do que uma inclusão lógica sob conceitos superiores abstratamente formulados". De imediato, é possível perceber que, para Alexy, a atividade de julgar é muito mais complexa do que a mera escolha de qual norma (independentemente se regra ou princípio) será aplicada ao caso concreto, o que prontamente revela quão perigoso é o caminho pelo qual se pretende seguir ao se atribuir a sistemas de IA a prerrogativa de julgar.

Segundo Alexy, o fundamento do Direito não é nem formal (como no positivismo), nem material (como no jusnaturalismo): tal fundamento é procedimental. O direito ganha, assim, uma dimensão moral que não significa a crença em uma ordem natural, mas sim a ideia de que a legitimidade do ordenamento jurídico depende do procedimento de sua produção e 
aplicação, que deve ser democrático e racionalizado. Isso significa dizer que, diante de um mesmo caso, as regras do discurso jurídico permitem que seus partícipes cheguem a conclusões racionais, todas fundamentadas discursivamente, mas incompatíveis entre si, o que se dá por uma série de motivos (ALEXY, 2001).

A crítica alexyana ao juspositivismo é empreendida com a publicação do livro Conceito e Validade do Direito, no qual o autor alemão sistematiza seu pensamento, de modo a melhor definir e conceituar seus pensamentos, fechando o sistema por ele desenhado, possibilitando a sistematização da sua obra e o delineamento de um sistema jusfilosófico coerente. Assim, tal obra não apenas representa a elaboração mais madura das reflexões filosóficas do autor acerca do conceito do direito, como também ela forma um importante elo entre as teses por desenvolvidas por Alexy durante o seu percurso intelectual (TOLEDO, 2015, p. 41-42). A discussão central e que direciona a obra é anunciado logo em suas primeiras páginas, quando o autor aduz:

O principal problema na polêmica acerca do conceito de direito é a relação entre direito e moral. Apesar de uma discussão de mais de dois mil anos, duas posições fundamentais continuam se contrapondo: a positivista e a não positivista. Todas as teorias positivistas defendem a tese da separação. Esta determina que o conceito de direito deve ser definido de modo que não inclua elementos morais. [...] Em contrapartida, todas as teorias não positivistas defendem a tese da vinculação. Esta determina que o conceito de direito deve ser definido de modo que contenha elementos morais (ALEXY, 2009, p. 3-4).

Nesse ponto, ao mesmo tempo em que Alexy apresenta as duas posições centrais acerca da filosofia do direito no que diz respeito ao direito e à moral ao longo dos séculos, também demarca o objeto principal de seu livro, que é investigar o conceito de direito. Destarte, o autor procura apreender quais são as características que afirmam o direito como elemento singular, o diferenciando dos demais objetos da natureza e do fazer humano. Para tanto, Alexy investiga se o direito, para além das propriedades formais que o identificam, possui propriedades morais intrínsecas, das quais não seja possível desvincular o conceito de direito " (MOREIRA, 2016).

Nessa toada, Alexy afirma que a procedimentalidade da teoria da argumentação jurídica se vincula aos limites de um modelo procedimental de quatro graus, quais sejam: o discurso prático geral; o procedimento legislativo; o discurso jurídico; e o procedimento judicial. Assim, uma premissa que chega ao discurso jurídico obrigatoriamente terá passado por todas as regras do discurso prático racional geral e por todo o debate do procedimento legislativo, sendo positivado como lei. Com base em tal Direito posto, 
“... a argumentação jusfundamental, especialmente com as formas e regras da interpretação na justificação externa", busca atingir seu objetivo, que seria "a determinação de direitos definitivos a partir dos direitos prima facie assegurados pela declaração principiológica dos direitos fundamentais" (TOLEDO, 2005, grifos no original).

E isso se dá devido ao fato de os princípios jurídicos apresentarem-se para Alexy como mandamentos de otimização, passíveis de cumprimento em diferentes medidas ou graus. Destarte, a determinação de certo direito fundamental como direito definitivo somente se revela possível na ocorrência do caso concreto. Conclui-se:

Todo esse percurso para a determinação, no caso concreto trazido ao procedimento judicial, de direitos definitivos a partir de direitos prima facie apenas se faz discursivamente, seguindo-se, de maneira imprescindível, às formas e regras da argumentação jurídica para ser tida como racional, ou seja, como correta - a despeito, mais uma vez, de não se afirmar como a única necessariamente possível. Formalmente, a controlabilidade da decisão somente pode ser feita, então, pelo exame do procedimento racional de justificação efetivado (TOLEDO, 2005, grifos no original).

É precisamente nesse ponto que se faz referência à possibilidade de um sistema jurídico inteligente exercer a atividade jurisdicional - permitir que a inteligência artificial "julgue”. Lança-se mão da justificativa do afastamento no maior grau possível de suposta arbitrariedade de um decisionismo na esfera dos três poderes e, em especial, no poder judiciário, para tentar tornar legítima a assunção do poder de julgar pela máquina. Em outras palavras, em favor da "neutralidade" do julgador, confia-se a um sistema jurídico inteligente o poder de decidir.

Diante de tal perspectiva, determinados autores se valem da noção de procedimentalidade da teoria da argumentação jurídica de Alexy para justificar a possibilidade de se atribuir a capacidade de tomada de decisão judicial a um sistema jurídico inteligente. Nessa visão, quando ocorre de a decisão de um caso concreto não se seguir logicamente nem das normas pressupostas, positivadas, nem de enunciados solidamente fundamentados de um sistema qualquer, e quando a decisão também não puder ser fundamentada definitivamente com a ajuda das regras da hermenêutica jurídica, restaria ao juiz, intérprete e aplicador do direito, um campo de ação: escolher entre várias soluções. Pela inteligência artificial, a partir de normas jurídicas positivadas, regras metodológicas e enunciados pré-estabelecidos em sistemas jurídicos inteligentes, as mesmas decisões poderiam ser tomadas. Assim, seriam possíveis, inclusive, decisões automáticas e programáveis. 
Contudo, como aponta Streck (2013), a decisão jurídica não pode ser entendida como um ato em que o juiz, ou, na hipótese com a qual trabalhamos, um software dotado de inteligência artificial, diante de várias possibilidades possíveis para a solução de um caso concreto, escolhe aquela que lhe parece mais correta, uma vez que decidir não é sinônimo de escolher. A escolha, isto é, a eleição de algo, é um ato de opção, o qual se dá "sempre que estamos diante de duas ou mais possibilidades, sem que isso comprometa algo maior do que o simples ato personificado em uma dada circunstância" (STRECK, 2013, p. 107). Assim, permitir que uma máquina tome determinada decisão em âmbito jurisdicional só seria possível se se concebesse o processo jurisdicional como uma mera escolha dentre as várias disponíveis, e sem que se considerasse a importância da hermenêutica e dos valores (éticos, sociais e morais) para tal processo.

Nas palavras de Mozetic (2017), "parece cristalino o fato de que Alexy delega aos sistemas jurídicos inteligentes essa possibilidade" [de decidir]. Discorda-se. Pois, segundo Alexy, a "tomada de decisão deveria (deveria no ponto de vista jurídico) ser orientada por julgamentos de valor moralmente corretos, do tipo relevante" (2001, p. 22). Assim, o discurso jurídico não deve "se mover de modo autossuficiente no interior de um universo hermeticamente fechado de Direito positivo vigente", mas sim estar constantemente aberto a argumentos de outras origens, como argumentos pragmáticos, éticos e morais (CARVALHO, 2013). Ademais, nos sistemas jurídicos em que os princípios contêm um conteúdo moralmente exigível, ou pelo menos admissível, há uma conexão necessária entre o direito e a moral correta (ALEXY, 2009, p. 93-94). Isso porque

a pretensão à correção implica uma pretensão à fundamentabilidade. Esta última não se restringe ao fato de a sentença ser fundamentável e, portanto, correta no sentido de uma moral qualquer, mas estende-se ao fato de a sentença ser correta no sentido de uma moral fundamentável e, portanto, correta. A conexão necessária entre o direito e a moral correta é estabelecida pelo fato de a pretensão à correção incluir uma pretensão à correção moral que se estende aos princípios que são tomados como base (ALEXY, 2009, p. 94-95).

Assim, a vigência das normas de direitos fundamentais significa que o sistema jurídico é um sistema aberto em face da moral (ALEXY, 2015, p. 545), o que não significa dizer, contudo, que exista uma relação de subordinação ou de secundariedade. Para Alexy, a decisão tomada em qualquer nível de fundamentação é, assim, uma decisão sobre o que deve 
ou pode ser feito ou omitido, o que envolve, necessariamente, uma valoração, ou juízo de valor (2013, p. 23). Nesse diapasão:

[...] não se quer dizer que o Direito é subordinado ou secundário em relação à Moral. Aliás, tal subordinação ou secundariedade é refutada pela afirmação da integração entre o discurso jurídico e o discurso prático racional geral. Há apenas a distinção entre essas duas esferas, na medida em que se elabora uma teoria do discurso de racionalidade, especificamente jurídica quando se cria a figura do caso especial. Com isso, o que se faz é a inter-relação entre discursos considerados apenas distintos, mas unidos na possibilidade e necessidade de sua racionalidade. Direito e Moral são entendidos, portanto, como complementares entre si (TOLEDO, 2005, grifos no original).

Um juiz, ao fundamentar uma determinada ponderação, sempre faz uso de um número substancial de argumentos morais, posto que os princípios sempre possuem uma essência axiológica, resultando que a pretensão à correção jurídica, atrelada a uma decisão, sempre abarca uma pretensão à correção moral. Já os sistemas jurídicos inteligentes partem do pressuposto de que é possível contar com uma visão neutra da representação da realidade. Assim o fazem pois tais sistemas "esquecem" ou ignoram que a legislação não trabalha com leis causais, sem perspectivas. O significado da norma só é alcançado após um processo de compreensão e interpretação, ou seja, hermenêutico, no qual os valores pessoais, dimensões culturais, éticas, sociais e emocionais muitas vezes desempenham um papel decisivo. Observe-se:

Tanto la IA como los sistemas expertos jurídicos parten del presupuesto de que es posible apoyarse en una visión neutral de la representación de la realidad (Ciencias naturales como la ingeniería, la física o la biología). Sin embargo, en el Derecho no se trabaja con leyes causales, no hay perspectivas neutras o desinteresadas. El significado de la norma sólo se logra tras un proceso interpretativo. Los valores personales, dimensiones culturales, éticas, sociales y emocionales juegan un papel decisivo. Es la manifestación de la textura abierta (open texture) del lenguaje jurídico. ¿Qué implicaciones tiene esto para la formalización simbólica? (BELLOSO MARTÍN, 2015, p. 132)

Alguns autores debruçaram-se sobre a questão da moralidade da inteligência artificial, questionando-se se um robô (ou software) com consciência artificial deveria ser considerado, ou não, um sujeito moral, e, por conseguinte, se conseguiria realizar valorações morais. Todavia, ainda que seja tentador buscar respostas à questão da ética e da moral considerando-se robôs como agentes moralmente autônomos, para um futuro previsível a moralidade da robótica envolverá necessariamente a ética humana na criação de programas com IA que sigam determinadas regras; não envolverá as regras morais e possíveis juízos de 
valor a serem realizadas por sistemas de IA como sistemas independentes (LIN, ABNEY e BEKEY, 2012, p. 50).

Diante disso, há que se considerar também, conforme aponta Searle, que seres humanos não seguem regras do mesmo modo que computadores o fazem, $i$. e., em observância a meros procedimentos formais. Na realidade, o computador não segue, de modo algum, quaisquer regras, mas sim executa apenas procedimentos formais. Afirmar que se obedece à regra é dizer que o significado desta regra, isto é, o seu conteúdo semântico, desempenha algum tipo de papel causal na produção do que efetivamente é feito. Assim, as propriedades formais da conduta não são suficientes para mostrar que uma regra deve ser seguida; para que a regra seja seguida, o significado da regra tem de desempenhar algum papel causal na conduta (SEARLE, 1997b, p. 58-60).

Ademais, é notório que os seres humanos, sem esforço algum, são capazes de identificar e de explicar o seu próprio comportamento e o das outras pessoas. Para Searle, esta capacidade se funda no nosso domínio inconsciente de um certo conjunto de princípios, da mesma maneira que a nossa capacidade de reconhecer uma frase escrita em outro idioma se baseia na posse de um domínio inconsciente dos princípios da gramática daquela língua (SEARLE, 1997b, p. 73). De certa forma, neste ponto, é possível lembrar da racionalidade prática proposta por Gadamer. A racionalidade prática, para Gadamer, é hermeneuticamente formada à medida que tem lugar central a "compreensão", que dá sentido ao que autor chama de "reunião em conselho". Em outras palavras, são os que estão próximos, como amigos, que determinam a nossa educação prática, e não uma consciência neutra e universal, e, assim, o mundo da vida concebido como mundo de valores já está posto em nossa lida com os outros; tais valores não necessitam ser fundados, mas podem ser criticados e modificados por meio da avaliação com os outros, de modo que a norma prática não surge na consciência de um eu, mas corresponde a este eu em suas determinações de horizontes (LINHARES, 2009). Assim, "são as implicações morais, na realidade, que se ligam a esse contraponto da racionalidade prática", não devendo a virtude da razão prática ser concebida como uma faculdade neutra que busca encontrar fins justos para meios práticos (GADAMER, 2009, p. 365).

Ainda segundo Searle, tem-se que a noção nuclear na estrutura do comportamento humano, e que, portanto, o difere da máquina, é a noção de intencionalidade (1997b, p. 74). Em síntese, a discussão da intencionalidade se resume à apreciação de três características que devem ser levadas em consideração na análise do comportamento humano: primeiramente, os chamados estados intencionais consistem num conteúdo em certo tipo mental. Em segundo 
lugar, tais estados intencionais determinam as suas próprias condições de satisfação, isto é, se serão ou não satisfeitas, dependendo do fato de se o Mundo se harmoniza com o conteúdo do estado. Por fim, em terceiro lugar, por vezes os estados intencionais fazem as coisas acontecer, mediante a causação intencional para produzir uma harmonia, isto é, para produzir o estado de coisas que representam as suas próprias condições de satisfação (1997b, p. 76).

Importa compreender a noção de intencionalidade pelo seguinte: os processos mentais de um ser humano existem independentemente de um observador (SEARLE, 1997a, p. 4), ao passo que os processos "mentais" de uma inteligência artificial são intencionais apenas na medida em que são interpretados como tal por um agente racional, posto que a IA meramente age como se possuísse crenças, desejos ou estados mentais próprios (1997c, p. 72). Os argumentos apresentados por Searle demonstram que sistemas de IA funcionam a partir de uma lógica puramente sintática, desprovida de conteúdo semântico; assim, apenas mimetizam o comportamento intencional através de parâmetros pré-estabelecidos de inputs e outputs.

Com efeito, em um Estado Democrático de Direito não se pode admitir que uma decisão judicial decorra do subjetivismo, isto é, do mero convencimento do juiz, sem que se proceda à argumentação; e também não é compatível o ato de um computador escolher, entre várias alternativas possíveis, uma que será considerada mais adequada. Pois, uma vez que nem mesmo um juiz poderia decidir sem usar argumentos racionais, não seria possível justificar a possibilidade de um sistema jurídico inteligente fazê-lo (UCHÔAS, 2018).

Tem-se ainda que determinados autores afirmam que o ato de julgar casos deveria ser comparado ao processo de jogos de azar, já que não haveria maneira de se estabelecer uma decisão única e correta (MAGALHÃES, 2004, p. 523-524), e assim justificam a possibilidade de se atribuir à IA a prerrogativa de julgar, decidir. Acredita-se na incorreção de tal argumento, pois, como aduzido alhures, as regras do discurso jurídico permitem que seus partícipes, diante de um mesmo caso concreto, cheguem a conclusões racionais corretamente fundamentadas mas incompatíveis entre si, o que não significa necessariamente a incorreção de uma ou mais de tais conclusões.

As regras do discurso, fundamento da argumentação jurídica, de fato, não definem nenhum procedimento que permita, mediante um número finito de operações, chegar a um resultado preciso, único, definitivo. $\mathrm{E}$ isso que se dá por três motivos: primeiramente, as regras do discurso não determinam o ponto de partida do procedimento (que correspondem às convicções normativas existentes e as interpretações de interesses dos participantes); em segundo lugar, as regras do discurso não estabelecem um passo-a-passo da argumentação, 
tampouco definem todos os passos a serem seguidos; por fim, uma série de regras de discurso só pode ser realizada aproximadamente, pois os discursos real e ideal não necessariamente se equivalem. Assim, a teoria do discurso não é uma teoria de decisão definida (ALEXY, 2001, p. 309). Ressalva-se que do fato de não se poder justificar a tese da existência de uma única resposta correta para cada pergunta prática não decorre que o conceito de correção não tenha um caráter e válido, pois ele possui o possui enquanto ideia reguladora (ALEXY, 2001, p. $311)$.

Ainda, os sistemas jurídicos inteligentes são passíveis de críticas devido ao fato de atenderem exclusivamente ao modo e critérios aplicados pelo seu criador, o programador. Como não é possível, por enquanto, se falar em uma inteligência artificial verdadeiramente autônoma, os softwares existentes operam de maneira condicionada, sempre respondendo aos inputs e outputs pré-determinados e estabelecidos por quem desenvolve o programa. Disso decorre que o resultado das eventuais decisões tomadas pelo computador continuará fortemente influenciado pelos valores, crenças e convicções da pessoa que criou a inteligência artificial, por mais que se busque uma pretensa imparcialidade e superação do subjetivismo.

É possível, como aponta Nuría Belloso Martín, reduzir a incerteza da linguagem jurídica, não obstante seja impossível elimina-la completamente, pois isso significaria afastar a decisão judicial dos valores pessoais e das dimensões culturais, éticas, sociais e emocionais que nela desempenham um papel decisivo:

Entendemos que se puede reducir la incertidumbre del lenguaje, pero no eliminarla completamente. Por todo ello, actualmente, no podemos considerar la IA y los SEJ más que como sistemas de apoyo y ayuda a la decisión pero no como sustitutivos de la capacidad de valorar y ponderar por parte del órgano judicial (BELLOSO MARTÍN, 2015, p. 132).

Assim, talvez seja necessário (re)pensar a teoria da decisão judicial na era pósmoderna, que deve se apresentar livre das amarras do subjetivismo do juiz, sujeito em que reside a razão prática, e também livre da busca por substituir a apreciação e valoração humanas por softwares dotados de inteligência artificial ou por sistemas jurídicos inteligentes. A filosofia do direito, com todas as contribuições já alcançadas, pode e deve buscar uma saída para o problema sobre o qual se discorre. Solução esta que abarque as teorias da argumentação, a hermenêutica jurídica, as considerações trazidas pela filosofia da mente fornecer, sem se olvidar dos avanços tecnológicos que se descortinam. 


\section{CONSIDERAÇÕES FINAIS}

É certo que a busca pela racionalidade da decisão - justificativa que leva à empreitada de construção e aperfeiçoamento de sistemas jurídicos inteligentes e softwares de inteligência artificial jurídicos - ocupa posição central para as teorias da argumentação jurídica, dentre as quais a de Alexy. No processo de decisão judicial, atribuir uma justificação racional a uma decisão significa dizer que, procedimentalmente, obteve-se uma tese adequada para um caso concreto sobre o qual se decide. Contudo, se, por um lado, a utilização da tecnologia possui a pretensão de contribuir para a justificação das decisões e, de outro, a argumentação jurídica mostra-se como a única forma de garantir uma decisão racionalmente justificada, o desenvolvimento de novas tecnologias não pode desconsiderar os preceitos das teorias da argumentação. À filosofia do direito, por sua vez, cabe não se afastar da realidade em transformação, permanecendo isolada no pequeno reduto da metodologia jurídica, da lógica computacional ou mesmo da ontologia.

A imagem de um juiz robô, ou uma máquina de decidir, continua sendo mais uma utopia na ideia de substituir o governo das pessoas pelo governo das máquinas. Considerandose que ainda hoje só existem sistemas baseados em inteligências artificiais fracas, é possível perceber que a evolução da informática não foi capaz de alcançar uma representação adequada de toda a complexidade ínsita ao Direito e ao processo de decisão judicial. Por mais completo e complexo que seja um sistema jurídico inteligente, uma máquina não pode substituir a capacidade de apreciação e valoração humana, tampouco pode motivar uma sentença, como deve fazer um juiz. A inteligência artificial pode e deve funcionar como ferramenta de auxílio para a tomada de decisões jurídicas e justificação das decisões, mas não como substituta à atividade humana.

Frente ao exposto, percebe-se que a inteligência artificial não pode integrar todos os elementos essenciais a uma decisão judicial, e o resultado obtido por um sistema jurídico inteligente dificilmente será impecavelmente justo e equitativo. Em que pese a existência de diferentes e sólidos argumentos contrários à ideia de se permitir que um sistema de IA ocupe o papel de juiz, é possível concluir que a atividade de julgar, principalmente por envolver processo de valoração, é uma atividade única e exclusivamente humana, e assim o permanecerá, ao menos por hora. 


\section{REFERÊNCIAS}

ALEXY, R. Conceito e validade do direito. Trad. Gercélia Batista de Oliveira Mendes. São Paulo: WMF Martins Fontes, 2009.

Sistema Jurídico e Argumentação no âmbito dos Direitos Fundamentais. In: Teoria dos Direitos Fundamentais. São Paulo: Malheiros, 2015. p. 543-574.

Teoria da argumentação jurídica: a teoria do discurso racional como teoria da fundamentação jurídica. Tradução de Zilda Hutchinson Schild Silva. 3. ed. Rio de Janeiro: Forense, 2013.

. Teoria da Argumentação Jurídica. São Paulo: Landy, 2001.

ALMEIDA, H. L. . A relação entre direito e moral em Robert Alexy. In: XXV ENCONTRO NACIONAL DO CONPEDI, 2016, BRASÍLIA/DF. Filosofia do direito I. Florianópolis: CONPEDI, 2016. p. 61-81.

ARNOLD FOUNDATION. Public Safety Assessment: A risk tool that promotes safety, equity, and justice. Disponível em: < http://www.arnoldfoundation.org/public-safetyassessment-risk-tool-promotes-safety-equity-justice/>. Acesso em 02 jul. 2018.

Artificial Intelligence (AI) for the practice of law: An introduction. Disponível em: $<$ https://rossintelligence.com/ai-introduction-law/>. Acesso em: 06 set. 2018.

ATIENZA, M. Las razones del Derecho: Teorías de la argumentación jurídica. México, Universidad Nacional Autónoma de México/ Instituto de Investigaciones Jurídicas, 2005.

BELLOSO MARTÍN, N. Algunas reflexiones sobre la informática jurídica decisional. In: BAEZ, Narciso Leandro Xavier et al. O impacto das novas tecnologias nos direitos fundamentais. Joaçaba: Ed. Unoesc, 2015.

CANAL, R. Sobre a filosofia da mente de John Searle. Dissertação (Mestrado em Filosofia) - Faculdade de Filosofia e Ciências, Universidade Estadual Paulista. Marília, 2010.

CARVALHO, J. B. C. L. Sobre os limites da argumentação jurídica: a desconstrução do ativismo judicial fundado na ponderação de princípios e a reinvenção da legitimidade jurídica nos pensamentos de Jürgen Habermas e Chantal Mouffe. Prisma Jur, São Paulo, v. 12, n. 2, p. 649-710, jul./dez. 2013.

CELLA, J. R. G. ; WOJCIECHOWSKI, P. B. . INTELIGÊNCIA ARTIFICIAL NOS PROCESSOS JUDICIAIS ELETRÔNICOS. In: Orides Mezzaroba; Raymundo Juliano Rego Feitosa; Vladmir Oliveira da Silveira; Viviane Coêlho Séllos-Knoerr. (Org.). DIREITO E NOVAS TECNOLOGIAS. 1ed.São Paulo: Editora Clássica, 2014, v. 12, p. 271-300.

DUARTE, L. G. M.; GALIL, G. C. Inovações pós-positivistas nos paradigmas do direito administrativo brasileiro. Revista Eletrônica do Curso de Direito da UFSM , v. 12, p. 359386, 2017. 
EGGERS, W.; SCHATSKY, D.; VIECHNICKI, P. AI-augmented government: Using cognitive technologies to redesign public sector work. [S.1], 2017. Disponível em: $<$ https://www2.deloitte.com/insights/us/en/focus/cognitive-technologies/artificialintelligence-government.html>. Acesso em: 5 ago. 2018.

FLORIDI, L.; CATH, C.; MITTELSTADT, B.; WACHTER, S.; TADDEO, M. Artificial Intelligence and the 'Good Society': the US, EU, and UK approach. Science and Engineering Ethics. Springer, 2017, p. 1-24.

LINHARES, J. C. . A HERANÇA DA FENOMENOLOGIA HUSSERLIANA NA HERMENÊUTICA DE GADAMER. Pensando: Revista De Filosofia (UFPI) , v. 7, p. 97 109, 2016.

GADAMER, H.G. Verdade e Método II: Complementos e índice. Tradução de Enio Paulo Giachini; revisão de Márcia Sá Cavalcante Schuback; 4ª edição - Petrópolis, RJ: Vozes, 2009.

LIN, P.; ABNEY, K.; BEKEY, G. A. Robot ethics: the ethical and social implications of robotics. MIT press, 2012.

MAGALHÃES, R. V. Automatización del raciocinio jurídico: perspectivas y limites en la aplicación de la inteligencia artificial al derecho. 2004. Tese (Doutorado) - Facultad de Derecho, Universidad de Burgos, Burgos, Espanha, 2004.

MCCARTHY, J. What is artificial intelligence?. Stanford, 2000. Disponível em: <http://www-formal.stanford.edu/jmc/whatisai.pdf>. Acesso em: 5 ago. 2018.

MEHR, H. Artificial Intelligence for Citizen Services and Government. [S.1], 2017. Disponível

$<$ https://ash.harvard.edu/files/files/artificial_intelligence_for_citizen_services.pdf $>$. Acesso em: 5 ago. 2018.

MONTEIRO, M.; SAVEDRA, M. M. G. Metodologia da pesquisa jurídica. Rio de Janeiro: Renovar, 2001.

MOZETIC, V. A. Os sistemas jurídicos inteligentes e o caminho perigoso até a teoria da argumentação de Robert Alexy / The intelligent legal systems and the dangerous way to the argumentation theory of Robert Alexy. Revista Brasileira de Direito, Passo Fundo, v. 13, n. 3, p. 437-454, dez. 2017. ISSN 2238-0604. Disponível em: <https://seer.imed.edu.br/index.php/revistadedireito/article/view/1939>. Acesso em: 02 jul. 2018.

NOTÍCIAS STF. Inteligência artificial vai agilizar a tramitação de processos no STF. Disponível em: <http://www.stf.jus.br/portal/cms/verNoticiaDetalhe.asp?idConteudo=380038>. Acesso em: 02 jul. 2018.

RICHARDS, N. M.; SMART, W. D. How should the law think about robots?, 2013. Disponível em: <https://ssrn.com/abstract=2263363 >. Acesso em: jan. 2018.

SEARLE, J. A Redescoberta da Mente. São Paulo: Martins Fontes, 1997a. 

1997b.

Mente, cérebro e ciência. $4^{\mathrm{a}}$ ed. Tradução de Arthur Morão. Lisboa: Edições 70,

The mystery of consciousness. New York: The New York Review of Books, 1997c.

STRECK, L. L.. O que é isto - decido conforme minha consciência?. 4. ed. rev. Porto Alegre: Livraria do Advogado, 2013.

TOLEDO, C. O Pensamento de Robert Alexy como Sistema - Argumentação Jurídica, direitos Fundamentais, conceito e validade do Direito. In: O Pensamento de Robert Alexy como Sistema. (Org.). Rio de Janeiro, Editora Forense Universitária. 2017. P.29-50.

Teoria da Argumentação Jurídica. Veredas do Direito, Belo Horizonte. v. 2, n. 3, p. 47-65, jan-jun, 2005.2 Disponível em: <http://www.domhelder.edu.br/veredas_direito/pdf/4_28.pdf>. Acesso em: 05 ago. 2018.

UCHÔAS, B. R. ; ALVES, E. K. ; TOLEDO, C . Dirigismo Criminal - O Direito Penal das Predições Matemáticas. In: Diálogos sobre Direitos Humanos - Direitos Humanos, Direito Internacional e Integração. Juiz de Fora: HOMA - Centro Direitos Humanos e Empresa, 2017. v. 1.

UCHÔAS, B. R. Inovações tecnológicas aplicadas ao Direito: Hiperracionalidade Ou Irracionalidade? In: REIS, Isaac (Org.). Diálogos sobre retórica e argumentação, vol. 4. Curitiba: Alteridade Editora, 2018. 